\title{
PRAGMATIC OPTIONS OF THE DIALOGICAL TEXT AS A LANGUAGE UNIT ${ }^{1}$
}

\author{
Nadezhda N. Shpilnaya \\ Altai State Pedagogical University, Barnaul, Russia
}

\begin{abstract}
The purpose of the article is to analyse pragmatic variants of a dialogical text as a language unit. It is assumed that the pragmatic context of the dialogical text (dialogue) actualizing is associated with either informative or phatic intentions. Informative and phatic dialogues appear as pragmatic allotext of a dialogical text. The research methodology is based on the synthesis of derivational and anthropocentric language theories. The process of creating a dialogical text is considered, on the one hand, as a derivational process due to the suppositional relationship between the lexeme and the text, and on the other hand, as a process of interpreting the text in the pragmatic context of its actualization. The material for the study was the recording of oral and written speech of regular native speakers in an informal communication situation. The total number of analyzed speech patterns was 140 dialogic texts -70 texts of each communication type. It is stated that the pragmatic actualization of the dialogical text is associated with the realization of paradigmatic and syntagmatic connections of lexemes. It is revealed that the syntagmatic model of a dialogical text genesis in informative communication is an adjoining model. A paradigmatic model of dialogic text genesis in informative communication is synonymy. In phatic communication, an attachment model was identified as a syntagmatic model of the genesis of a dialogical text. The paradigmatic model for the production of dialogic text in phatic communication is a homonym model.

Key words: dialogical text, pragmatics, informative communication, phatic communication, derivation, paradigmatics, syntagmatics.

Citation. Shpilnaya N.N. Pragmatic Options of the Dialogical Text as a Language Unit. Vestnik Volgogradskogo gosudarstvennogo universiteta. Seriya 2. Yazykoznanie [Science Journal of Volgograd State University. Linguistics], 2021, vol. 20, no. 2, pp. 47-56. (in Russian). DOI: https://doi.org/10.15688/jvolsu2.2021.2.5
\end{abstract}

\section{ПРАГМАТИЧЕСКИЕ ВАРИАНТЫ ДИАЛОГИЧЕСКОГО ТЕКСТА КАК ЯЗЫКОВОЙ ЕДИНИЦЫ ${ }^{1}$}

\author{
Надежда Николаевна Шпильная \\ Алтайский государственный педагогический университет, г. Барнаул, Россия
}

\begin{abstract}
Аннотация. Цель статьи - анализ прагматических вариантов диалогического текста как языковой единицы. Предполагается, что прагматический контекст актуализации диалогического текста (диалогемы) связан либо с информативной, либо с фатической интенцией. Информативные и фатические диалогемы предстают как прагматические аллотексты диалогического текста. Методология исследования основана на синтезе деривационной и антропоцентрической теорий языка. Процесс создания диалогического текста рассматривается как деривационный процесс, обусловленный суппозиционной связью лексемы и текста, и как процесс интерпретации текста в прагматическом контексте его актуализации. Материалом для исследования послужили записи устной и письменной речи рядовых носителей языка в неофициальной ситуации общения. Общее количество проанализированных речевых произведений составило 140 диалогических текстов по 70 текстов каждого вида коммуникации. Установлено, что прагматическая актуализация диалогического текста связана с реализацией парадигматических и синтагматических связей лексем или их сочетаний. Выявлено, что синтагматическая модель генезиса диалогического текста в информативной коммуникации -
\end{abstract}




\section{РЕЧЕВЫЕ МЕХАНИЗМЫ И ЕДИНИЦЫ ТЕКСТОВОЙ КОММУНИКАЦИИ}

модель-примыкание. Парадигматическая модель генезиса диалогического текста в информативной коммуникации - синонимия. В фатической коммуникации выделена такая синтагматическая модель генезиса диалогического текста, как модель-присоединение. Парадигматическая модель производства диалогического текста в фатической коммуникации - модель-омоним.

Ключевые слова: диалогический текст, прагматика, информативная коммуникация, фатическая коммуникация, деривация, парадигматика, синтагматика.

Цитирование. Шпильная Н. Н. Прагматические варианты диалогического текста как языковой единицы // Вестник Волгоградского государственного университета. Серия 2, Языкознание. - 2021. - Т. 20, № 2. - С. 4756. - DOI: https://doi.org/10.15688/jvolsu2.2021.2.5

\section{Введение}

Объектом исследования в статье является диалогический текст как единица языка, а предметом - прагматические варианты его актуализации, обусловленные информативноориентированной и фатически-ориентированной интенциями, воплощаемыми в соответствующих им видах коммуникации. Фокус нашего внимания сосредоточен на варьировании моделей генезиса диалогического текста в информативной и фатической коммуникации. Под моделью генезиса понимается способ превербальной организации текста, актуализируемый в речи. Модель генезиса диалогического текста рассматривается в таком случае как способ его построения, подобно тому, как в словообразовании генезис производного слова описывается через понятие «способ словообразования».

К изучению вопроса о моделях производства диалогического текста лингвисты подходят с различных сторон: со стороны диалогической лингвистики и со стороны дериватологии. В диалогической лингвистике выделены иллокутивные модели создания диалогического текста, представляющие собой модели связи реплик на основе прагматических отношений: модели вопрос-ответ, согласиеотказ и пр. [Баранов, Крейдлин, 1992; Падучева, 1982]. В дериватологии в качестве моделей производства диалогического текста рассматриваются субъектно-предикатная, предикатно-аргументная, семантико-импликативная модели, модель актуального членения и прагматическая модель [Карасик, 1987]. Данные деривационные модели можно рассматривать как текстемы, или диалогемы, единицы эмического уровня, представляющие собой инварианты диалогического текста в системно-языковом аспекте.
Вопрос о лингвистическом статусе диалогического текста является дискуссионным. Так, выделяются три подхода к определению эмического статуса диалогического текста. Во-первых, диалогический текст рассматривается как проявление дифференциального признака текста - диалогичности, предполагающей создание текста в ситуации попеременного обмена репликами носителями языка [Холодович, 1979]. Во-вторых, диалогический текст рассматривается как вариант структурной организации текста, специфика которого заключается в том, что он представляет собой цельное, но не единичное высказывание, актуализирующее разные точки зрения [Валгина]. В-третьих, диалогический текст рассматривается как самостоятельная единица языка, выделяемая на синтагматических основаниях, подобно слогу [Шпильная, 2018].

В данной работе развивается положение о самостоятельном статусе диалогического текста. Следовательно, для описания диалогического текста считаем целесообразным использовать противопоставление «единица языка - единица речи», или оппозицию «инвариант - вариант». Проецируя описание единиц языка и речи, существующее в лингвистической вариантологии [Голев, Ким, 2009; Рабенко, Лебедева, 2018; Солнцев, 1984], на описание диалогического текста, отметим, что вопрос об инвариантно-вариантном существовании диалогического текста является открытым в современной лингвистике.

В исследовании мы опираемся на положение, согласно которому речевая актуализация единиц языка сопряжена с их интерпретацией как будущей единицей речи с учетом речевой и внеречевой среды ее актуализации. Среда при данном подходе предстает как контекст, определяющий специфику актуализаци- 
онного процесса и его результат. Для диалогического текста такими контекстами являются экстралингвистический контекст, включающий условия произнесения речи, место, время, обстановку, социальный статус носителя языка и пр., прагматический контекст, связанный с варьированием коммуникативной интенции, и текстовый контекст, создаваемый в речевой цепи предшествующим и последующим текстами.

В статье анализируется только прагматический контекст актуализации языковой единицы - диалогемы (текстемы). Иными словами, рассматриваются прагматические условия его актуализации, связанные либо с интенцией на обмен информацией, либо с интенцией на поддержание коммуникативного взаимодействия. Этот подход представляется целесообразным в силу того, что вариант языковой единицы существует в определенном речевом оформлении - речевом контексте (речевой среде, по А.В. Бондарко). Для диалогического текста им является прагматический контекст, что соотносится с пониманием языка как знаковой системы и одним из аспектов ее измерения - прагматическим, связанным с отношением «знак - интерпретатор» [Моррис, 2001]. Отметим, что прагматический аспект знакообразования рассматривается обычно с позиций адресата или адресанта как участников коммуникации, однако такое понимание связи знака и интерпретатора кажется чрезмерно упрощенным, поскольку представляется, что отношение «знак - интерпретатор» определяет прагматику языкового знака в самой языковой системе, которая проявляется в интерпретации знака на вышестоящем уровне языковой системы (структуры) при его актуализации в речи. Гипотетический характер данного положения нуждается в верификации, однако мы полагаем, что оно отражает реальное положение дела. Так, фонема интерпретируется на морфемном уровне, морфема на лексическом, граммема на синтаксическом и т. д. Прагматический контекст, или прагматическая среда, диалогического текста предстает в таком случае как интерпретация диалогемы (текстемы) в зависимости от коммуникативной интенции носителя языка. Данный подход к описанию языка базируется на положении о том, что отношения между языковой единицей и ее речевой манифестацией - это отношения интерпретации инварианта с учетом образа будущей речевой среды его актуализации [Шпильная, 2019].

Исследуя проблему варьирования диалогического текста в прагматическом контексте, обратимся к характеристике информативной и фатической коммуникаций. Как известно, они представляют собой эквиполентную оппозицию, которую можно рассматривать как инвариантную по отношению к другим разновидностям коммуникации. Информативная коммуникация связана с реализацией информативного речевого поведения, а фатическая коммуникация - с реализацией фатического речевого поведения. О противопоставлении данных видов коммуникации написано немало работ (см., например: [Винокур, 1993]), в них отмечается, что эти виды коммуникации различаются по ряду параметров, и прежде всего по коммуникативным намерениям участников коммуникации и по жанровому составу.

В статье развивается положение, согласно которому специфика коммуникации определяется интенцией носителя языка, реагирующего на исходную реплику. Иными словами, мы полагаем, что если носитель языка реализует намерение запроса информации или ее уточнения, то это проявление информативной коммуникативной интенции, а если носитель языка реализует намерение подключения к разговору для его поддержания, то это уже проявление фатической интенции.

Логично предположить, что если коммуникативные намерения участников общения различны и обусловливают разные типы речевого поведения, то и модели генезиса диалогического текста как реальной единицы коммуникации различаются в данных видах коммуникации. Таким образом, можно полагать, что информативные и фатические диалогемы (текстемы) предстают как прагматические аллотексты диалогического текста.

\section{Методология и материал исследования}

Методология нашего исследования основана на синтезе деривационной и антропоцентрической теорий языка, что обусловлено 


\section{РЕЧЕВЫЕ МЕХАНИЗМЫ И ЕДИНИЦЫ ТЕКСТОВОЙ КОММУНИКАЦИИ}

необходимостью продемонстрировать особенности диалогического текста как производной единицы, возникающей вследствие реализации принципа деривации, и особенности его речевой актуализации, связанной с речевой интерпретацией диалогемы (текстемы) с учетом прагматического контекста ее реализации (актуализации).

Диалогический текст рассматривается в работе как производная единица языка, подобная производному слову.

Значимым для нас является развиваемый в современной дериватологии тезис о том, что генезис диалогического текста определяется деривационными процессами, ключевой из которых - выводимость целого из его части - текста из лексемы. Данное положение базовое для дериватологии, изучающей процесс производства языковых единиц от фонемы до текста - и рассматривающий этот процесс как суппозиционную связь языковых единиц. Например, связь лексического и текстового уровней была доказана в работах сибирских дериватологов [Голев, 1989; Сайкова, 2002; Трубникова, 2008], которые рассматривают лексему (лексический ряд) в качестве основы при образовании текста.

Теоретическое обоснование принцип суппозиционной связи лексемы и текста получил в наших предыдущих публикациях (см., например: [Шпильная, 2018]). Согласно данному принципу, образование текста (диалогического текста) осуществляется на основе лексемы как свернутого текста, который может актуализироваться в речи за счет парадигматических и синтагматических связей ключевых лексем в языковом сознании носителя языка. Лексема в этом случае рассматривается как база для развития темы текста. Характер внешнего согласования лексем как опорных точек будущего диалогического текста определяет ту или иную вербальную модель его актуализации. Актуализация диалогического текста связывается нами с реализацией принципа суппозиционной связи лексемы и текста, который обусловливает генезис и функционирование диалогического текста в актах его производства / воспроизводства. Такая позиция согласуется с эмпирическими наблюдениями ученых, рассматривающих проблему связности дистантных реплик в ди- алогическом тексте (см., например: [Шестакова, 2005]).

Материалом для исследования послужили записи устной и письменной речи рядовых носителей языка в неофициальной ситуации общения. Для выявления моделей производства диалогического текста в информативной коммуникации мы обратились к анализу обыденного сетевого политического общения, для выявления моделей производства диалогического текста в фатической коммуникации - к анализу личностноориентированных дискурсивных практик: к разговорам преподавателей одного из сибирских вузов в ситуации общения на перемене, по дороге домой. Избранный для анализа языковой материал обладает спецификой, обусловленной экстралингвистическим контекстом его существования, однако полагаем, что экстралингвистический контекст важен для информативной коммуникации, для фатической коммуникации он становится несущественным. Поэтому особенности реализации диалогического текста в информативной коммуникации - в обыденной сетевой политической коммуникации - ограничены именно этим экстралингвистическим контекстом, которым мы не можем пренебречь, но в силу сфокусированности на решаемых в статье задачах не рассматриваем.

Общее количество проанализированных речевых произведений составило 140 диалогических текстов - по 70 текстов каждого вида коммуникации.

\section{Результаты}

\section{1. Модели генезиса диалогического текста в информативной коммуникации}

Как мы уже отмечали, информативная коммуникация связана с реализацией информативного речевого поведения, предполагающего ориентацию на целенаправленный обмен информацией. Наши наблюдения над языковым материалом показывают, что генезис диалогического текста в информативной коммуникации осуществляется по разным моделям - синтагматической и парадигматической. 
В качестве текста-основы, или текстаобъекта, рассматривается текст новостной статьи, содержание которой можно представить в форме пропозиции:

Губернатор Новосибирской области Василий Юрченко распорядился до 1 августа очистить все вестибюли новосибирского метрополитена от торговых киосков в целях обеспечения безопасности жителей города от терактов.

\section{1. Синтагматические модели генезиса диалогического текста}

Синтагматические модели генезиса диалогического текста реализуются посредством проявления в информативной коммуникации синтагматических связей ключевых лексем, образующих его семантическое пространство. Специфика вербализации данной модели определяется тем, что в тексте-цели ключевой лексемы может не быть, однако в нем представлены лексические единицы, соотносимые с исходной синтагматически. Выделяется такая синтагматическая модель генезиса диалогического текста, как модель-

\section{примыкание.}

Она характеризуется тем, что во второй реплике появляются лексемы, находящиеся в синтаксической зависимости с лексемой из исходной реплики по линии координации. Условно такую связь можно представить в виде формулы, задающей коммуникативную перспективу высказывания по линии его рематизации: «известное + новое». Иными словами, примыкание здесь рассматривается как коммуникативно значимое присоединение диктумного элемента.

Приведем примеры (здесь и далее орфография и пунктуация оригиналов сохранены).

(1) Давно пора! Торговля в метро - пережиток 90х!!! Я хочу ездить в метро, а нужные товары покупать в магазинах!!! Этож сколько нужно взяток одним только пожарным давать, что бы они закрывали глаза на торговлю в вестибюлях метро. Бардак пора прекращать уже и вести дела цивилизованно.

Специфика появления данной реплики заключается в том, что в ней использовано выражение пережиток 90x, примыкающее к выражению торговля в метро как свернутому тексту пропозиции. Ср.: пережиток $90 x+$ торговля в метро.

(2) А мне фиолетово: пусть убирают, только не верю я что все киоски уберут, все равно оставят союзпечать, и еще парочку...

В данном примере выражение nycms убирают связано по линии координации с пропозициональным содержанием текста-основы торговые киоски. Следовательно, реализуется модель-примыкание: nусть убирают + торговые киоски.

(3) А кто нибудь помнит в Новосибирске хоть один теракт????

Данная реплика появляется за счет примыкания словоформы помнит к элементу пропозиционального содержания реплики-основы теракт. Ср.: помнит + теракт.

\section{2. Парадигматические модели генезиса диалогического текста}

Парадигматические модели генезиса диалогического текста в информативной коммуникации предполагают актуализацию в текстецели лексем, находящихся в отношениях синонимии с лексемами из текста-объекта. Нами выделена одна парадигматическая модель производства диалогического текста в информативной коммуникации - синонимия, которая актуализирует разные события, контекстуально сближаемые носителями языка. Так, во второй реплике появляется лексема-синоним, которая служит средством актуализации события, ситуативно близкого обсуждаемому событию, закрепленному соответствующей лексемой в первой реплике.

(4) Будем теперь ходить поздними вечерами по пустынным длинным мрачным вестибюлям.., сжимая в страхе газовый баллончик в потной ладони.. бррр..

В тексте-цели устанавливаются реляционные отношения - уподобление - между ключевыми лексемами из текста-объекта вестибюли [метро], безлюдный уголок и междометием бррр, служащим вербальным показателем эмоциональной ситуации страха, 


\section{РЕЧЕВЫЕ МЕХАНИЗМЫ И ЕДИНИЦЫ ТЕКСТОВОЙ КОММУНИКАЦИИ}

о чем свидетельствует использование слов и словосочетаний страх, газовый баллончик, потная ладонь, пустынныий длинный мрачный вестибюль. В данном случае происходит развитие события за счет последовательного появления в диалоге нового события, контекстуально близкого обсуждаемому: новосибирский метрополитен - бррр.

(5) Будет как в ташкентском метро - ни рекламы, ни киосков. Только плакаты «Бдительность основа безопасности» повсюду и полицейские на каждом входе и выходе. Если несешь пакет-проверят два раза.

Как видим, данный текст - это результат реализации парадигматических сцепок ключевых лексем - новосибирский метрополитен и ташкентское метро, которые синонимизируются носителем языка. Развитие события текста-основы происходит за счет введения нового события, контекстуально связанного с исходным: новосибирское метро ташкентское метро.

\section{2. Модели генезиса диалогического текста в фатической коммуникации}

Фатическая коммуникация ориентирована на поддержание контакта между носителями языка и не предполагает обмен информацией в прагматических целях. На основе анализа эмпирического материала выделены парадигматическая и синтагматическая модели генезиса диалогического текста.

\section{1. Синтагматические модели генезиса диалогического текста}

В фатической коммуникации представлена модель-присоединение. Она обычно реализуется за счет использования присоединительных конструкций кстати, а ещзе, $а$ $я$ ( а у меня, а у нас). Рассмотрим примеры.

(6) - Я завтра на больничный иду...

- Кстати, по поводу больничного. Ты не знаешь, а мне заплатят за замену?

В приведенном примере вторая реплика вводится при помощи присоединительной конструкции кстати, которая позволяет носите- лю языка актуализировать свое событие, имеющее ту же речевую форму, что и событие другого участника коммуникации (больничный - больничного).

(7) - Вчера пиццу делала.

- А я вчера тоже пиццу хотела, но не стала стряпать, мы купили в магазине. Вкусная была.

Как видим, диалог осуществляется за счет второй реплики, в которой используется конструкция $a$ я, присоединяющая два события, обсуждаемых носителями языка.

\section{2. Парадигматическая модель генезиса диалогического текста}

Эмпирический материал позволил выделить одну парадигматическую модель генезиса диалогического текста - модельомоним.

При ее актуализации развитие диалога осуществляется с опорой на ключевую лексему текста-основы, которая служит суппозицией для генезиса текста-цели и развития темы диалога. При этом ключевые лексемы актуализируют разные события, которые на поверхностном уровне воспринимаются как омонимичные в силу общей речевой формы актуализации или одного и того же референтного значения лексемы (в последнем случае речь идет о людях, ставших предметом обсуждения в диалоге). На внешнем уровне связь ключевых лексем обеспечивает когезию в диалогическом высказывании.

(8) - Мне нужны волонтеры на Тотальный диктант. Сообщаю Вам, что я Ксению записала волонтером на акцию Тотальный диктант.

- Ну если она не против. Кстати, по поводу Тотального диктанта. Я готовила девочку на всероссийский конкурс. У нее была тема по тотальному диктанту. Отражение культурных ценностей в текстах тотального диктанта. Она заняла второе место. Сегодня вот как раз поеду на награждение.

Как видим, ключевым является словосочетание Тотальный диктант, которое служит базой для развития темы в диалоге и средством связи реплик. При этом участники диалога актуализируют разные - как бы омонимичные - события, обозначенные ключевой единицей. 
(9) - Я вчера пришла домой. Голодная жуть. Хотела картошку погреть в микроволновке. А она у меня сломалась. Пришлось греть на плите.

- Повезло... А у меня вчера холодильник сломался. Пришлось мастера вызывать. Я думала, что он не сразу приедет, а он сразу приехал. Приехал и все починил.

В приведенном примере реплики связаны повтором лексемы вчера, которая играет роль общего сирконстанта, определяющего логику развития диалога в фатической коммуникации и попеременную интерактивную актуализацию разных (омонимичных) событий, обозначенных одной и той же лексемой сломался.

(10) - А я подсела на Билли Айлиш.

- А кто это?

- Это американская певица, очень эпатажная.

- Да, а еще. Я слышала, что какая-то девочка нарисовала ее портрет, представляете этот портрет опубликовал какой-то женский журнал на обложке, так достоверно получилось.

В диалоге первая и четвертая реплики объединены событиями, которые имеют общий референт - Билли Айлиш: в первой реплике используется речевая форма имени собственного, а в четвертой - субститутивная замена (местоимение ее). В этих репликах представлена актуализация разных событий, связанных с одним и тем же референтом.

\section{Обсуждение результатов}

Исследование прагматических вариантов актуализации моделей генезиса диалогического текста в фатической и информативной коммуникации уточняет существующие на сегодняшний день представления об инвариантновариантном устройстве диалогического текста. $\mathrm{OH}$, долгое время рассматриваемый в качестве единицы речи или структурного варианта организации речевой формы (текста), не описывался как самостоятельная единица языка, в частности с позиций дихотомии язык - речь, или инвариант - вариант.

Сложность изучения диалогического текста в вариантологическом аспекте определяется гносеологическим желанием лингвиста максимально учесть условия его создания. Однако мы полагаем, что собственно лингвистический путь решения такой задачи пред- полагает опору на семиотическую природу языкового знака. Следовательно, выделение прагматических вариантов диалогического текста не противоречит, а, наоборот, соответствует прагматическому измерению языкового знака, которое может быть описано в рамках отношений «знак - интерпретатор».

Прагматическая актуализация диалогического текста, как мы показали, связана с реализацией синтагматических и парадигматических связей слов и словосочетаний. Это в некоторой степени соответствует представлению языка как многорелейной системы, описываемой А. Кибриком [1965] и предполагающей выводимость одного уровня через другой за счет возможности обращения носителя языка к единицам этого уровня для «строительства» требуемой единицы. Как следствие, синтагматика и парадигматика лексем определяют инвариантные модели генезиса диалогического текста и их прагматическое распределение в разных видах коммуникации, в частности информативной и фатической.

Синтагматическая модель генезиса диалогического текста в информативной коммуникации - модель-примыкание - соотносится с реализацией коммуникативной перспективы высказывания, что позволяет говорить о связи прагматической интерпретации диалогического текста с развитием события. Парадигматическая модель генезиса диалогического текста в информативной коммуникации связана с отношениями синонимии, что, по нашему мнению, показывает изоморфизм лексической и текстовой парадигматики на превербальном уровне организации текста.

В фатической коммуникации была выделена такая синтагматическая модель генезиса диалогического текста, как модельприсоединение, которая реализует намерение носителя языка подключиться к разговору за счет актуализации другого события. Наличие парадигматической модели производства диалогического текста в фатической коммуникации - модели-омонима - не только демонстрирует изоморфизм лексической и текстовой парадигматики, но и показывает, что в ней актуализируются два разных события, соотносимые с адресантом и адресатом как участниками коммуникации и имеющие омонимичную форму воплощения. 


\section{РЕЧЕВЫЕ МЕХАНИЗМЫ И ЕДИНИЦЫ ТЕКСТОВОЙ КОММУНИКАЦИИ}

Важно отметить, что варианты лексической парадигматики - синонимия и омонимия распределяются по разным видам коммуникации: синонимия обнаруживается в информативной коммуникации, а омонимия - в фатической. Синтагматические модели генезиса диалогического текста тоже характеризуются прагматическим перераспределением: в информативной коммуникации актуализируется модель-примыкание, а в фатической - модель-присоединение.

\section{Выводы}

В работе сформулирована гипотеза о том, что речевая актуализация диалогемы (текстемы) в прагматическом контексте связана с реализацией различных моделей производства диалогического текста как производной единицы языка. Это положение было конкретизировано в тезисе, согласно которому модели производства диалогического текста варьируются в разных видах коммуникации - фатической и информативной - актуализирующих различные коммуникативные намерения носителей языка.

С опорой на положения дериватологии и антропоцентрической лингвистики процесс создания диалогического текста был рассмотрен, с одной стороны, как деривационный процесс, обусловленный суппозиционной связью лексемы и текста, а с другой стороны, как процесс интерпретации текста в прагматическом контексте его актуализации.

Выделены и описаны модели производства диалогического текста в информативной и фатической коммуникации, специфика которых определяется актуализацией различных языковых механизмов текстообразования - синтагматических и парадигматических.

Информативные и фатические модели диалогического текста создаются за счет актуализации синтагматических и парадигматических механизмов языковой деятельности. Причем парадигматические и синтагматические модели диалогического текста в информационной и фатической коммуникации варьируются, поскольку в информационной коммуникации происходит развитие одного события, а в фатической коммуникации - интерактивная актуализация разных (омонимич- ных) событий, осуществляемая попеременно участниками диалога.

\section{ПРИМЕЧАНИЕ}

${ }^{1}$ Работа подготовлена при поддержке гранта Президента РФ для молодых ученых - докторов наук МД-3824.2021.2.

The work was prepared with the support of the grant of the President of the Russian Federation for young scientists - Doctor of Sciences MD3824.2021.2.

\section{СПИСОК ЛИТЕРАТУРЫ}

Баранов А. Н., Крейдлин Г. Е., 1992. Иллокутивное вынуждение в структуре диалога // Вопросы языкознания. № 2. С. 84-99.

Валгина Н. C. Теория текста. URL: http://www.hiedu.ru/e-books/xbook029/01/ (дата обращения: 21.02.2020).

Винокур Т. Г., 1993. Говорящий и слушающий : Варианты речевого поведения. М. : Наука. 172 с.

Голев Н. Д., 1989. Динамический аспект лексической мотивации. Томск : Изд-во Том. ун-та. $252 \mathrm{c}$.

Голев Н. Д., Ким Л. Г., 2009. Вариативно-интерпретационное функционирование текста (к вопросу о расширении границ лингвистической вариантологии) // Вестник Челябинского государственного университета. Филология. Искусствоведение. Вып. 34, № 27. С. 12-20.

Карасик В. И., 1987. О производности высказываний // Деривация и история языка : межвуз. сб. науч. тр. / под ред. Л. Н. Мурзина. Пермь : Перм. ун-т. С. 92-102.

Кибрик А. Е., 1965. Лингвистические вопросы автоматического кодирования // Теоретические проблемы прикладной лингвистики. М. : Изд-во МГУ.

Моррис Ч. У., 2001. Основания теории знаков // Семиотика. Антология. М. : Акад. проект ; Екатеринбург : Деловая кн. С. 45-97.

Падучева Е. В., 1982. Прагматические аспекты связности диалога // Известия АН СССР. Серия литературы и языка. Т. 41, № 4. С. 305-313.

Рабенко Т. Г., Лебедева, Н. Б., 2018. Речевой жанр в фокусе вариантологической модели языка (на материале речевого жанра «личная записка») // Культура и текст. № 1. С. 144-152.

Сайкова Н. В., 2002. Взаимодействие слова и текста в деривационном аспекте (на материале вторичных текстов разных типов) : дис... канд. филол. наук. Барнаул. 163 с. 
Солнцев В. М., 1984. Вариативность как общее свойство языковой системы // Вопросы языкознания. № 2. С. 31-42.

Трубникова Ю. В., 2008. Лексико-деривационные основания моделирования текста. Барнаул : Изд-во Алт. ун-та. 180 с.

Холодович А. А., 1979. О типологии речи // Проблемы грамматической теории. Л. : Наука. C. 269-276.

Шестакова Т. Э., 2005. Дистантные связи диалогических реплик в тексте драмы : дис. ... канд. филол. наук. Ярославль. 207 с.

Шпильная Н. Н., 2018. Русский диалогический текст: деривационная концепция. М. : ЛЕНАНД. $384 \mathrm{c}$.

Шпильная Н. Н., 2019. Деривационно-интерпретационный процесс и его следствия при объяснении языковых явлений в системе русского языка // Филология и человек. № 3. С. 7-18.

\section{REFERENCES}

Baranov A.N, Kreydlin G.E., 1992. Illokutivnoe vynuzhdenie v strukture dialoga [Illocutionary coercion in the structure of dialogue]. Voprosy yazykoznaniya, no. 2, pp. 84-99.

Valgina N.S. Teoriya teksta [Text Theory]. URL: http:// www.hi-edu.ru/e-books/xbook029/01/ (accessed 21 February 2020).

Vinokur T.G., 1993. Govoryashchiy i slushayushchiy: Varianty rechevogo povedenijya [Talking and Listening. Variants of Speech Behavior]. Moscow, Nauka Publ. 172 p.

Golev N.D., 1989. Dinamicheskiy aspekt leksicheskoy motivatsii [Dynamic aspect of lexical motivation]. Tomsk, Izd-vo Tomskogo universiteta. $252 \mathrm{p}$.

Golev N.D., Kim L.G., 2009. Variativnointerpretatsionnoe funktsionirovanie teksta $(\mathrm{k}$ voprosu o rasshirenii granits lingvisticheskoy variantologii) [Variable-interpretative functioning of the text (on the issue of expanding the boundaries of linguistic variantology)]. Vestnik Cheljabinskogo gosudarstvennogo universiteta. Filologiya. Iskusstvovedenie [Bulletin of Chelyabinsk State University. Philology. Art criticism], iss. 34, no. 27, pp. 12-20.

Karasik V.I., 1987. O proizvodnosti vyskazyvaniy [On derivative statements]. Murzin L.N., ed. Derivatsyja i istoriya yazyka [Derivation and History of Language]. Perm, Permskiy universitet, pp. 92-102.

Kibrik A.E., 1965. Lingvisticheskie voprosy avtomaticheskogo kodirovaniya [Linguistic issues of automatic coding]. Teoreticheskie problemy prikladnoy lingvistiki [Theoretical problems of applied linguistics]. Moscow, Izd-vo MGU.

Morris Ch.U., 2001. Osnovaniya teorii znakov [Foundations of the theory of signs]. Semiotika. Antologiya [Semiotics. Anthology]. Moscow, Akademicheskiy proekt Publ.; Ekaterinburg, Delovaja kniga Publ., pp. 45-97.

Paducheva E.V., 1982. Pragmaticheskie aspekty svyaznosti dialoga [Pragmatic aspects of dialogue connectivity]. Izvestiya AN SSSR. Seriya literatury $i$ yazyka [Proceedings of the USSR Academy of Sciences. Series of literature and language], vol. 41, no. 4, pp. 305-313.

Rabenko T.G., Lebedeva N.B., 2018. Rechevoj zhanr v fokuse variantologicheskoj modeli jazyka (na materiale rechevogo zhanra «lichnaja zapiska») [Speech genre focus variantology language model (based on the speech genre of "personal note")]. Kultura i tekst, no. 1, pp. 144-152.

Saykova N.V., 2002. Vzaimodeystvie slova i teksta $v$ derivatsionnom aspekte (na materiale vtorichnykh tekstov raznykh tipov): dis... kand. filol. nauk [Interaction of a word and a text in the derivational aspect (based on the material of secondary texts of various types). Cand. philol. sci. diss.]. Barnaul. 163 p.

Solntsev V.M., 1984. Variativnost kak obshchee svoystvo yazykovoy sistemy [Variability as a general property of a linguistic system]. Voprosy yazykoznaniya, no. 2, pp. 31-42.

Trubnikova Yu.V., 2008. Leksiko-derivatsionnye osnovaniya modelirovaniya teksta [Lexicoderivational foundations of text modeling]. Barnaul, Izd-vo Altayskogo universiteta. 180 p.

Holodovich A.A., 1979. O tipologii rechi [On the typology of speech]. Problemy grammaticheskoy teorii [Problems of grammatical theory]. Leningrad, Nauka Publ.,pp. 269-276.

Shestakova T.Ye., 2005. Distantnye svyazi dialogicheskikh replik $v$ tekste dramy [Distant communications of dialogical remarks in the text of a drama. Cand. philol. sci. diss.]. Yaroslavl. $207 \mathrm{p}$.

Shpilnaya N.N., 2018. Russkiy dialogicheskiy tekst: derivacionnaya kontsepciya [The Russian dialogical text: derivational concept]. Moscow, LENAND Publ. 384 p.

Shpilnaya N.N., 2019. Derivatsionnointerpretatsionnyy process i ego sledstviya pri ob\#yasnenii yazykovykh yavleniy $\mathrm{v}$ sisteme russkogo yazyka [The derivationalinterpretational process and its consequences in explaining linguistic phenomena in the Russian language system]. Filologiya $i$ chelovek [Philology and a human being], no. 3, pp. 7-18. 


\section{РЕЧЕВЫЕ МЕХАНИЗМЫ И ЕДИНИЦЫ ТЕКСТОВОЙ КОММУНИКАЦИИ}

\section{Information About the Author}

Nadezhda N. Shpilnaya, Doctor of Sciences (Philology), Professor, Department of General and Russian Linguistics, Altai State Pedagogical University, Molodezhnaya St, 55, 656031 Barnaul, Russia, venata85@mail.ru,https://orcid.org/0000-0002-0709-4308

\section{Информация об авторе}

Надежда Николаевна Шпильная, доктор филологических наук, профессор кафедры общего и русского языкознания, Алтайский государственный педагогический университет, ул. Молодежная, 55, 656031 г. Барнаул, Россия, venata85@mail.ru, https://orcid.org/0000-0002-0709-4308 